\title{
RESPOSTA DA CULTURA DA SOJA (Glycine max L. Merril) À APLICAÇÃO DE ACETATO DE ZINCO AMONIACAL VIA SEMENTE
}

\author{
Marcos Vinicius Ribas Milléo ${ }^{1}$, Isadora Cristófoli ${ }^{2}$ \\ ${ }^{1}$ Professor Doutor, Departamento de Fitotecnia e Fitossanidade, UEPG, e-mail: oellim@ig.com.br; \\ ${ }^{2}$ Acadêmica do curso de Agronomia, UEPG, e-mail: isadoracristofoli@gmail.com
}

\begin{abstract}
RESUMO: Com o objetivo de avaliar a resposta da soja à aplicação de acetato de zinco amoniacal (ACA Plus) via semente, desenvolveram-se três trabalhos em campos experimentais distintos, no decorrer das safras 2012/13, 2013/14 e 2014/15, nos respectivos municípios paranaenses: Cornélio Procópio, Palmeira e Ponta Grossa. O delineamento foi em blocos casualizados, contendo 5 tratamentos e 4 repetições. Os tratamentos foram: 1) Controle absoluto (sem adubação de base e sem tratamento de semente); 2) Controle (sem tratamento de semente); 3) ACA Plus - fonte de nitrogênio + zinco (2 mL kg-1 de semente); 4) ACA Plus (4 mL kg${ }^{-1}$ de semente); 5) FortSeed Dry - fonte de cobalto+molibdênio (2,0 $\mathrm{g} \mathrm{kg}^{-1} \mathrm{de}$ semente). A partir das médias dos dados relativos às três safras, relatou-se que com a aplicação de ACA Plus, quanto à aplicação de cobalto e molibdênio, houve incrementos significativos para: altura de plantas, massa fresca de raízes, massa seca de raízes e número de vagens por planta. Consequentemente, as maiores produtividades foram obtidas mediante a aplicação do ACA Plus. A aplicação de ACA Plus via sementes é uma técnica viável e que pode melhorar o estande final da cultura da soja
\end{abstract}

Palavras-chave: plantio direto, tratamento de sementes, micronutrientes, produtividade

\section{SOYBEAN (Glycine max L. Merril) RESPONSE TO THE APPLICATION OF AMMONIACAL ZINC ACETATE VIA SEED}

\begin{abstract}
In order to evaluate soybean response to the ammoniacal zinc acetate (ACA Plus) application via seed, three trials were developed in different experimental fields during the seasons of 2012/13, 2013/14 and 2014/15, in the respective cities: Cornélio Procópio, Palmeira and Ponta Grossa. The design was in randomized blocks, with 5 treatments and 4 replications. The treatments were: 1) Absolute control (without any fertilizer and without treatment seeds); 2) Control (without seeds treatment); 3) ACA Plus - nitrogen source + zinc (2 mL kg-1 seed); 4) ACA Plus (4 mL kg-1 seed); 5) FortSeed Dry - cobalt+molybdenum (2 $\mathrm{g}$ $\mathrm{kg}^{-1}$ seed). From the average obtained from the three seasons data's, it was reported that with the application of ACA Plus, compared to the application of cobalt and molybdenum, there were significant increases for: plant height, roots fresh and dry matter, number of pods per plant. Consequently, the highest yields were obtained by applying the ACA Plus. The application of ACA Plus via seeds is a practicable technique that can improve the final stand of the soybean crop.
\end{abstract}

Key-words: no tillage, seed treatment, micronutrients, productivity 


\section{INTRODUÇÃO}

A soja (Glycine max (L.) Merril), é uma leguminosa pertencente à classe Dicotyledoneae. É uma planta herbácea, ereta, de ciclo anual e de crescimento morfológico diversificado, o qual depende do hábito de crescimento, podendo variar de 0,3 a 2,0 m de altura, com ciclo de 80 a 200 dias aproximadamente, dependendo da cultivar e das condições climáticas (SEDIYAMA et al., 1993).

A soja é a principal oleaginosa fornecedora de proteína e óleo vegetal no mundo, possuindo teores nas faixas de $37 \%$ a $40 \%$ e de $18 \%$ a $22 \%$, respectivamente. É grandemente utilizada na alimentação humana, para atender tanto o mercado interno quanto o externo, e também na fabricação de rações para animais. Aproximadamente $70 \%$ do farelo proteico presente em rações animais é proveniente da soja (EMBRAPA, 2010).

Conforme o levantamento da safra brasileira de grãos 2014/2015, divulgado em Abril pela Conab (2015), a produção estimada para a safra foi de $94.280,5$ milhões de toneladas, enquanto a média de produtividade brasileira se encontrou na ordem de $2.993 \mathrm{~kg} \mathrm{ha}^{-1}$, sendo portanto, este grão o principal produto da exportação brasileira.

De acordo com Marschner, citado por Yamada, (1995) e Fancelli (2003), a nutrição mineral nem sempre pode ser visualizada, como por exemplo, na produtividade, mas pode proporcionar um aumento da resistência das plantas aos patógenos, além de influenciar no crescimento e na produção das plantas cultivadas, causando modificações na forma de crescimento, na morfologia, na fisiologia, na anatomia e na sua composição química, gerando descendentes mais vigorosos em casos de produção de sementes.

No estabelecimento da cultura, que vai do desenvolvimento vegetativo ao reprodutivo da cultura da soja, podem ocorrer fatores antagonistas ou sinergistas que irão determinar um maior ou menor rendimento da cultura. Esse rendimento final depende dos fatores de produção que são: número de plantas por hectare, número de vagens por planta, número de grãos por vagem e da massa dos grãos. Entre estes componentes o segundo é considerado o de 
maior importância (MALAVOLTA et al., 1997). Segundo Mengel \& Kirkby (1987) os fatores climáticos têm sua responsabilidade, mas os nutrientes têm papel fundamental para minimizar os fatores adversos.

A adoção de medidas culturais capazes de melhorarem o desenvolvimento horizontal da parte aérea e do sistema radicular possibilita aumentar a eficiência da planta em absorver água e nutrientes, proporcionando uma maior produtividade em função do aumento dos componentes da produção. A aplicação de nutrientes e aditivos específicos via sementes proporcionam a cultura uma melhor nutrição e um melhor equilíbrio fisiológico facilitando o seu manejo para alcançar altas produtividades.

O nitrogênio é o elemento mineral que as plantas exigem em maiores quantidades. Ele serve como constituinte de muitos componentes da célula vegetal, incluindo aminoácidos e ácidos nucleicos. Portanto, a deficiência de nitrogênio rapidamente inibe o crescimento vegetal. Se tal deficiência persiste, a maioria das espécies mostra clorose, sobretudo nas folhas mais velhas (TAIZ \& ZEIGER, 2004).

O cobalto é absorvido pelas raízes na forma $\mathrm{Co}^{2+}$, sendo considerado móvel no floema. Porém, quando aplicado via foliar, é parcialmente móvel. É um nutriente essencial para a fixação biológica do nitrogênio, pois participa na síntese de cobamida e da leghemoglobina (EMBRAPA, 2004).

O molibdênio (Mo) está presente em menos de um ppm na matéria seca e é componente essencial de duas enzimas importantes para as plantas, a nitrogenase e a nitrato redutase. A nitrogenase é essencial no mecanismo de fixação simbiótica de nitrogênio pelas bactérias fixadoras de $\mathrm{N}_{2}$ atmosférico, e a nitrato redutase atua no mecanismo de redução do nitrato a amônia na planta. Assim, a ausência de Mo pode causar sintomas de deficiência de nitrogênio nas plantas (MALAVOLTA et al., 1997). Vários são os métodos que podem ser empregados para a aplicação de Mo, desde a aplicação no solo, a aplicação foliar até o tratamento de sementes (MALAVOLTA et al., 1997).

O zinco participa como componente de um grande número de enzimas, tais como as desidrogenases, proteinases, peptidases e fosfohidrolases. Suas funções básicas na planta 
estão relacionadas ao metabolismo de carboidratos, proteínas e fosfatos, na formação de estruturas das auxinas, RNA e ribossomos (BORKERT, 1989), e no metabolismo de fenóis, na multiplicação e aumento de tamanho das células, e na fertilidade do grão de pólen (MALAVOLTA et al., 1991). O zinco também é importante para a síntese de clorofila. A deficiência de zinco é caracterizada pela redução do crescimento internodal e, como resultado, a planta apresenta um hábito de crescimento rosetado. A velocidade e a taxa de germinação podem ser menores. As folhas podem ser também pequenas e retorcidas e de aparência enrugada. Tais sintomas podem resultar da perda da capacidade de produzir quantidades adequadas de ácido indolacético (AIA), pois o zinco é essencial para a síntese do triptofano que, por sua vez, é precursor do AIA. Em algumas espécies (milho, sorgo, feijão), as folhas mais novas podem tornar-se cloróticas entre as nervuras e desenvolver manchas necróticas brancas (TAIZ \& ZEIGER, 2004).

Acetato de zinco amoniacal (ZC) pode proporcionar o crescimento radicular em um grande número de culturas, tais como milho e canola (PACHOLCZAK \& SZYDLO, 2008). Culturas tratadas com ZC têm apresentado maior volume de raiz, maior resistência à seca, proporcionando maior produtividade (PACHOLCZAK \& SZYDLO, 2008). O mecanismo de ação do ZC é diferente dos cofatores auxínicos típicos (PACHOLCZAK \& SZYDLO, 2008). Quando aplicado, ele estimula a biossíntese da auxina endógena, resultando na relação de troca auxina/citocinina o que incrementa a formação de raiz (PACHOLCZAK \& SZYDLO, 2008), bem como, podendo modular a produção de giberelina favorecendo o processo de germinação das sementes e emergência das plantas. Portanto, o objetivo deste trabalho foi avaliar a resposta da cultura da soja (Glycine $\max$ L. Merril) a aplicação de acetato de zinco amoniacal (ACA Plus) via semente.

\section{MATERIAL E MÉTODOS}

Os experimentos foram conduzidos em três campos experimentais distintos, sendo que, um na cidade de Palmeira - PR, na Estação Experimental Agrícola Campos Gerais a $882 \mathrm{~m}$ de altitude, no segundo planalto Paranaense, nas coordenas geográficas $25^{\circ} 25^{\prime} 34^{\prime \prime} \mathrm{S}$ e 50²'56”' O. O clima da região é Cfb segundo Koeppen, sempre úmido, quente temperado, sem estação seca definida e com geadas frequentes no inverno. $\mathrm{O}$ solo onde foi conduzido o 
experimento é de textura média e classificado de acordo com Embrapa (2006) como um CAMBISSOLO Distrófico. A análise de solo, para a amostragem de 0 a $20 \mathrm{~cm}$, apresentou os seguintes resultados: $\mathrm{pH} \mathrm{CaCl}=4,8 ; \mathrm{Ca}^{++}=4,78 \mathrm{cmol}_{\mathrm{c}} \mathrm{dm}^{-3} ; \mathrm{Ca}^{++}+\mathrm{Mg}^{++}=6,54 \mathrm{cmol}_{\mathrm{c}} \mathrm{dm}^{-}$ ${ }^{3} ; \mathrm{K}+=0,11 \mathrm{cmol}_{\mathrm{c}} \mathrm{dm}^{-3} ; \mathrm{P}=5,90 \mathrm{mg} \mathrm{dm}^{-3} ; \mathrm{Al}^{+++}=0,16 \mathrm{cmol}_{\mathrm{c}} \mathrm{dm}^{-3} ; \mathrm{C}=20,26 \mathrm{~g} \mathrm{dm}^{-3}$. A data de semeadura na safra 2012/13 foi no dia 17/01/2013, onde se utilizou adubação química durante a semeadura, da fórmula comercial 02-20-20 na quantidade de $380 \mathrm{~kg} \mathrm{ha}^{-1}$.

O segundo experimento foi conduzido na Fazenda Escola Capão da Onça (FESCON) localizado no município de Ponta Grossa - PR a $988 \mathrm{~m}$ de altitude, no segundo planalto Paranaense, nas coordenas geográficas $25^{\circ} 05^{\prime} 30.96^{\prime}$ ' S e $50^{\circ} 03^{\prime} 07.72$ '’ O. O clima da região é também caracterizado como $\mathrm{Cfb}$, segundo a classificação de Koeppen. O solo onde foi conduzido o experimento é de textura média e classificado de acordo com Embrapa (2006) como um CAMBISSOLO Distrófico. A análise de solo, para a amostragem de 0 a $20 \mathrm{~cm}$, apresentou os seguintes resultados: $\mathrm{pH} \mathrm{CaCl} 2=5,2 ; \mathrm{Ca}++=4,00 \mathrm{cmol}_{\mathrm{c}} \mathrm{dm}^{-3} ; \mathrm{Ca}^{++}+\mathrm{Mg}^{++}=$ $5,2 \mathrm{cmol}_{\mathrm{c}} \mathrm{dm}^{-3} ; \mathrm{K}^{+}=0,10 \mathrm{cmol}_{\mathrm{c}} \mathrm{dm}^{-3} ; \mathrm{P}=14,4 \mathrm{mg} \mathrm{dm}^{-3} ; \mathrm{Al}^{+++}=0,00 \mathrm{cmol}_{\mathrm{c}} \mathrm{dm}^{-3} ; \mathrm{C}=19 \mathrm{~g}$ $\mathrm{dm}^{-3}$. A semeadura na safra 2013/14 ocorreu no dia 23/12/2013. Fez-se adubação química durante a semeadura, utilizando-se a fórmula comercial 02-20-20 na quantidade de $350 \mathrm{~kg} \mathrm{ha}^{-}$ 1.

O terceiro experimento foi conduzido na Fazenda Sonato localizada no município de Cornélio Procópio - PR a 510 m de altitude, no terceiro planalto Paranaense, nas coordenas geográficas $23^{\circ} 09^{\prime} 20.60^{\prime \prime}$ S e 50³7'05.43’’ O. O clima da região é Cfa segundo Koeppen, com verões quentes, geadas pouco frequentes e tendência de concentração das chuvas nos meses de verão, entretanto sem estação seca definida. O solo onde foi conduzido o experimento é de textura argilosa e classificado de acordo com Embrapa (2006) como um LATOSSOLO Vermelho distroférrico. A análise de solo, para a amostragem de 0 a $20 \mathrm{~cm}$, apresentou os seguintes resultados: $\mathrm{pH} \mathrm{CaCl} 2=4,73 ; \mathrm{Ca}^{++}=5,48 \mathrm{cmol}_{\mathrm{c}} \mathrm{dm}^{-3} ; \mathrm{Ca}^{++}+\mathrm{Mg}^{++}$ $=6,93 \mathrm{cmol}_{\mathrm{c}} \mathrm{dm}^{-3} ; \mathrm{K}^{+}=0,36 \mathrm{cmol}_{\mathrm{c}} \mathrm{dm}^{-3} ; \mathrm{P}=22,13 \mathrm{mg} \mathrm{dm}^{-3} ; \mathrm{Al}^{+++}=0,10 \mathrm{cmol}_{\mathrm{c}} \mathrm{dm}^{-3} ; \mathrm{C}=$ $15,52 \mathrm{~g} \mathrm{dm}^{-3}$. A semeadura ocorreu no dia 08/12/2014 da safra 2014/15. Fez-se adubação química durante a semeadura, utilizando-se a fórmula comercial 02-20-20 na quantidade de $300 \mathrm{~kg} \mathrm{ha}^{-1}$. 
O delineamento experimental utilizado foi em blocos ao acaso com cinco tratamentos e quatro repetições (KOEHLER, 1994). As parcelas experimentais apresentaram área útil de 8,1 $\mathrm{m}^{2}(1,35 \mathrm{~m} \times 6,0 \mathrm{~m})$ e área total de $32,0 \mathrm{~m}^{2}$.

A cultivar de soja utilizada nas três safras foi a BMX Potencia RR, colocando-se em média 18 sementes por metro, em espaçamento de $0,45 \mathrm{~m}$ entre linhas, a uma profundidade de 3 a $6 \mathrm{~cm}$.

Por ocasião da colheita, foi avaliado o estande final (E), a altura das plantas (AP), os componentes do rendimento: número de vagens por planta (NVP), massa fresca de raiz, durante a floração, (MFR), massa seca raiz (MSR) e produtividade (P). O estande final foi obtido pela contagem do número total de plantas por área útil, utilizando-se a média nas duas safras. Os grãos foram provenientes da debulha automática de todas as vagens, que forneceram por pesagem o rendimento de sementes (corrigidos a $13 \%$ de umidade e transformados em $\mathrm{kg} \mathrm{ha}^{-1}$ ).

Os tratamentos, doses e modo de aplicação se encontram na Tabela 1.

Tabela 1. Tratamentos, nome comercial, dose e modo de aplicação dos produtos utilizados nos ensaios com soja. Locais: Estação Experimental Agrícola Campos Gerais, Palmeira, PR, safra 2012/13, Fazenda Escola Capão da Onça (FESCON), Ponta Grossa, PR, safra 2013/14 e Fazenda Sonato, Cornélio Procópio, PR, safra 2014/15.

\begin{tabular}{|c|c|c|c|}
\hline Tratamento & $\begin{array}{l}\text { Nome Comercial do } \\
\text { produto usado no } \\
\text { tratamento de semente }\end{array}$ & Dose ${ }^{(1)}$ & $\begin{array}{l}\text { Modo de } \\
\text { Aplicação }\end{array}$ \\
\hline 1 - Controle absoluto & $* *$ & $\begin{array}{c}\text { Sem adubação de base e } \\
\text { sem tratamento de } \\
\text { semente }\end{array}$ & ------ \\
\hline 2 - Controle & $* *$ & $\begin{array}{l}\text { Sem tratamento de } \\
\text { semente }\end{array}$ & ---- \\
\hline 3 - Acetato de zinco amoniacal & ACA Plus & $2,0 \mathrm{~mL} \mathrm{~kg}^{-1}$ semente & Via semente \\
\hline 4 - Acetato de zinco amoniacal & ACA Plus & $4,0 \mathrm{~mL} \mathrm{~kg}^{-1}$ semente & Via semente \\
\hline
\end{tabular}


5 - Cobalto + Molibdênio

FortSeed Dry

$2,0 \mathrm{~g} \mathrm{~kg}^{-1}$ semente

Via semente

\section{CARACTERIZAÇÃO DOS PRODUTOS EM ESTUDO}

1) Nome comercial: ACA Plus

Classe: Fertilizante foliar

pH: 6,43

Garantias: N - 7,0\%; Zn - 8,5\%

Tipo de Formulação: Solução verdadeira

Registrante: FORTGREEN COMERCIAL AGRÍCOLA LTDA

2) Nome comercial: FortSeed Dry

Classe: Fertilizante sólido

pH: 7,1

Garantias: Co $-1,5 \%$; Mo $-30,0 \%$

Tipo de Formulação: Pó solúvel

Registrante: FORTGREEN COMERCIAL AGRÍCOLA LTDA

\section{METODOLOGIA DE AVALIAÇÃO}

Avaliou-se o estande final, a altura de plantas, massa fresca e seca de raiz, número de vagens por planta e a produtividade. Os dados obtidos foram submetidos à análise da variância e quando significativas às diferenças entre as médias (teste de F), estas foram comparadas pelo teste de t (DMS) ao nível de 5\% de probabilidade, utilizando-se o software SISVAR (FERREIRA, 2008). 


\section{RESULTADOS E DISCUSSÃO}

A análise de variância dos dados referentes à avaliação do uso do acetato de zinco amoniacal, do cobalto e molibdênio em tratamento de sementes na cultura da soja revelou por meio do teste "F" que houve diferença estatística significativa entre os tratamentos nas variáveis testadas.

Para o parâmetro estande final de plantas na safra 2012/13, há diferenças significativas entre os tratamentos, T3, T4 e T5, e não demonstrando diferença entre os tratamentos T1 e T2. Esta diferença aponta claramente que a aplicação dos fertilizantes via semente melhorou o estande das plantas em relação aos dois tratamentos controle, e também, demonstra que a aplicação ACA Plus (acetato de zinco amoniacal) nos dois tratamentos T3 e T4 apresentaram os maiores valores de estande final de plantas (Tabela 2). Analisando os dados médios de estande de plantas para a safra 2013/14, podemos notar que há diferença entre os tratamentos T1 e T2, e os demais T3, T4 e T5, ficando claro que a aplicação dos fertilizantes via semente também melhoraram o estande final das plantas em relação aos dois tratamentos controle, T1 e T2 respectivamente, repetindo os resultados da safra anterior (Tabela 3). Da mesma maneira, na safra 2014/15 os tratamentos T3 e T4 foram superiores a todos os demais (Tabela 2, 3 e 4). Os tratamentos T3 e T4 apresentaram os melhores resultados médios de estande final nas três safras, corroborando com Santos (1981) e Parducci et al. (1989), em que a aplicação de nutrientes via sementes teve vantagem da maior uniformidade na distribuição e a racionalização no uso das reservas naturais não renováveis, por causa das pequenas quantidades utilizadas e aproveitadas pelas plantas.

Analisando os dados das três safras nas Tabelas 2, 3 e 4, pode-se notar que há diferença nas produtividades médias dos tratamentos, e este fato deve-se a problemas edáficos e climáticos enfrentados na safra 2012/13, fator este não observado nas safras 2013/14 e 2014/15. 
Tabela 2. Estande (E) em número de plantas por metro linear, altura de plantas (AP), massa fresca de raiz (MFR), massa seca de raiz (MSR), número de vagens planta $^{-1}$ (NVP) e produtividade (P) de soja obtida na avaliação do uso do acetato de zinco amoniacal aplicados via sementes. Palmeira, PR. Safra 2012/13.

\begin{tabular}{|c|c|c|c|c|c|c|c|}
\hline Tratamentos & $\begin{array}{l}\text { Doses } \\
\mathrm{mL} \mathrm{kg}^{-} \\
1 / / \mathrm{g} \\
\mathrm{kg}^{-1}\end{array}$ & $\begin{array}{c}* \mathbf{E} \\
\text { (plantas } \mathrm{m}^{-} \\
{ }^{1} \text { ) }\end{array}$ & $\begin{array}{l}\mathbf{A P} \\
(\mathrm{cm})\end{array}$ & $\begin{array}{c}\text { MFR } \\
(\mathrm{g})\end{array}$ & $\operatorname{MSR}(\mathrm{g})$ & $* \mathbf{N V P}$ & $\begin{array}{c}\mathbf{P} \\
\left(\mathrm{kg} \mathrm{ha}^{-1}\right)\end{array}$ \\
\hline $\begin{array}{c}1 \text { Controle } \\
\text { Absoluto }\end{array}$ & 0 & $11,50 \mathrm{c}$ & $16,03 \mathrm{c}$ & $1,25 \mathrm{c}$ & $0,33 \mathrm{c}$ & $1,13 \mathrm{c}$ & $1611,33 b$ \\
\hline 2 Controle & 0 & $12,50 \mathrm{c}$ & $17,68 \mathrm{~b}$ & $1,42 \mathrm{c}$ & $0,33 \mathrm{c}$ & $1,17 \mathrm{c}$ & $1790,00 \mathrm{~b}$ \\
\hline $\begin{array}{c}3 \text { Acetato de } \\
\text { zinco } \\
\text { amoniacal }\end{array}$ & 2 & $15,50 \mathrm{ab}$ & $18,90 \mathrm{ab}$ & $2,08 \mathrm{~b}$ & $0,67 \mathrm{~b}$ & $1,35 \mathrm{~b}$ & $2640,60 \mathrm{a}$ \\
\hline $\begin{array}{c}4 \text { Acetato de } \\
\text { zinco } \\
\text { amoniacal }\end{array}$ & 4 & $16,00 \mathrm{a}$ & $19,13 \mathrm{a}$ & $2,08 \mathrm{~b}$ & $0,58 \mathrm{bc}$ & $1,33 \mathrm{~b}$ & $2361,00 \mathrm{a}$ \\
\hline $\begin{array}{l}5 \text { Cobalto + } \\
\text { Molibdênio }\end{array}$ & 2 & $14,75 \mathrm{~b}$ & $17,98 \mathrm{ab}$ & $2,58 \mathrm{a}$ & $1,00 \mathrm{a}$ & $1,40 \mathrm{a}$ & $2600,00 \mathrm{a}$ \\
\hline CV\% & & 1,92 & 19,14 & 33,52 & 76,37 & 11,68 & 9,46 \\
\hline
\end{tabular}

*Variável transformada em $\log (\mathrm{x})$ - dados de contagem, Médias seguidas de mesma letra na coluna, não diferem entre si ao nível de significância de 5\% pelo Teste t (DMS) de Fisher. 
Tabela 3. Estande (E) em número de plantas por metro linear, altura de plantas (AP), massa fresca de raiz (MFR), massa seca de raiz (MSR), número de vagens planta ${ }^{-1}$ (NVP) e produtividade (P) de soja obtida na avaliação do uso do acetato de zinco amoniacal aplicados via sementes. Fazenda Escola Capão da Onça, Ponta Grossa, PR. Safra 2013/14.

\begin{tabular}{|c|c|c|c|c|c|c|c|}
\hline Tratamentos & $\begin{array}{c}\text { Doses } \\
\\
\mathrm{mL} \mathrm{kg}^{-} \\
1 / \mathrm{g} \\
\mathrm{kg}^{-1}\end{array}$ & $\begin{array}{c}* \mathbf{E} \\
\left(\begin{array}{c}\text { plantas } \\
\left.\mathrm{m}^{-1}\right)\end{array}\right.\end{array}$ & $\begin{array}{l}\mathbf{A P} \\
(\mathrm{cm})\end{array}$ & $\begin{array}{c}\text { MFR } \\
\text { (g) }\end{array}$ & $\begin{array}{c}\text { MSR } \\
\text { (g) }\end{array}$ & $* \mathbf{N V P}$ & $\begin{array}{c}\mathbf{P} \\
\left(\mathrm{kg} \mathrm{ha}^{-1}\right)\end{array}$ \\
\hline $\begin{array}{l}1 \text { Controle } \\
\text { Absoluto }\end{array}$ & 0 & $11,5 \mathrm{c}$ & $39,23 \mathrm{~d}$ & $20,25 \mathrm{~d}$ & $7,00 \mathrm{c}$ & $1,53 \mathrm{a}$ & $2973,25 \mathrm{e}$ \\
\hline 2 Controle & 0 & $12,5 \mathrm{~b}$ & $43,50 \mathrm{~b}$ & $22,50 \mathrm{~d}$ & $8,00 \mathrm{c}$ & $1,57 \mathrm{a}$ & $3303,50 \mathrm{~d}$ \\
\hline $\begin{array}{c}3 \text { Acetato de zinco } \\
\text { amoniacal }\end{array}$ & 2 & $15,5 \mathrm{a}$ & $45,93 \mathrm{a}$ & $39,50 \mathrm{c}$ & $13,25 \mathrm{a}$ & $1,55 \mathrm{a}$ & $5212,00 \mathrm{~b}$ \\
\hline $\begin{array}{l}4 \text { Acetato de zinco } \\
\text { amoniacal }\end{array}$ & 4 & $15,5 \mathrm{a}$ & $46,33 \mathrm{a}$ & $43,25 \mathrm{~b}$ & $8,25 \mathrm{a}$ & $1,54 \mathrm{a}$ & $5613,00 \mathrm{a}$ \\
\hline $\begin{array}{l}5 \text { Cobalto + } \\
\text { Molibdênio }\end{array}$ & 2 & $16,25 \mathrm{a}$ & $42,43 \mathrm{c}$ & $48,50 \mathrm{a}$ & $13,25 \mathrm{a}$ & $1,56 \mathrm{a}$ & $4677,25 \mathrm{c}$ \\
\hline CV\% & & 1,90 & 6,25 & 12,26 & 11,75 & 8,42 & 3,40 \\
\hline
\end{tabular}

Médias seguidas de mesma letra na coluna, não diferem entre si ao nível de significância de 5\% pelo Teste t (DMS) de Fisher. 
Tabela 4. Estande (E) em número de plantas por metro linear, altura de plantas (AP), massa fresca de raiz (MFR), massa seca de raiz (MSR), número de vagens planta ${ }^{-1}$ (NVP) e produtividade (P) de soja obtida na avaliação do uso do acetato de zinco amoniacal aplicados via sementes. Fazenda Sonato, Cornélio Procópio, PR. Safra 2014/15.

\begin{tabular}{|c|c|c|c|c|c|c|c|}
\hline Tratamentos & $\begin{array}{l}\text { Doses } \\
\\
\mathrm{mL} \mathrm{kg}^{-} \mathrm{kg}^{-} \\
\mathrm{g} \mathrm{kg}^{-}\end{array}$ & $\begin{array}{c}* \mathbf{E} \\
(\text { plantas } \\
\mathrm{m}^{-1} \text { ) }\end{array}$ & $\begin{array}{l}\mathbf{A P} \\
(\mathrm{cm})\end{array}$ & $\begin{array}{c}\text { MFR } \\
(\mathrm{g})\end{array}$ & $\begin{array}{c}\text { MSR } \\
(\mathrm{g})\end{array}$ & $* \mathbf{N V P}$ & $\begin{array}{c}\mathbf{P} \\
\left(\mathrm{kg} \mathrm{ha}^{-1}\right)\end{array}$ \\
\hline $\begin{array}{c}1 \text { Controle } \\
\text { Absoluto }\end{array}$ & 0 & $11,5 \mathrm{~b}$ & $82,57 \mathrm{c}$ & $19,34 \mathrm{e}$ & $6,32 \mathrm{~d}$ & $33,25 \mathrm{~b}$ & $3696,13 \mathrm{~b}$ \\
\hline 2 Controle & 0 & $12,5 \mathrm{~b}$ & $91,75 \mathrm{~b}$ & $21,49 \mathrm{~d}$ & $7,25 \mathrm{c}$ & $37,00 \mathrm{~b}$ & $3887,50 \mathrm{~b}$ \\
\hline $\begin{array}{c}3 \text { Acetato de } \\
\text { zinco } \\
\text { amoniacal }\end{array}$ & 2 & $15,25 \mathrm{a}$ & $95,50 \mathrm{ab}$ & $35,5 \mathrm{~b}$ & $11,75 \mathrm{~b}$ & $48,50 \mathrm{a}$ & 4383,33 a \\
\hline $\begin{array}{l}4 \text { Acetato de } \\
\text { zinco } \\
\text { amoniacal }\end{array}$ & 4 & $16,75 \mathrm{a}$ & 98,75 a & $38,75 \mathrm{a}$ & $15,00 \mathrm{a}$ & $47,50 \mathrm{a}$ & $4337,50 \mathrm{a}$ \\
\hline $\begin{array}{l}5 \text { Cobalto + } \\
\text { Molibdênio }\end{array}$ & 2 & $13,25 \mathrm{~b}$ & $96,00 \mathrm{ab}$ & $33,25 \mathrm{c}$ & $11,75 \mathrm{~b}$ & $40,50 \mathrm{ab}$ & $4104,17 \mathrm{ab}$ \\
\hline CV\% & & 8,39 & 3,28 & 2,14 & 5,68 & 15,34 & 6,74 \\
\hline
\end{tabular}

Ao realizar a checagem dos dados das médias de todos os parâmetros realizados relativos à safra 2012/13 da Estação Agropecuária dos Campos Gerais, observou-se que os tratamentos que tiveram a adição de acetato de zinco amoniacal e cobalto + molibdênio isoladamente, apresentaram diferença em relação ao controle absoluto sem fertilizantes aplicados no plantio e sobre o controle sem aplicação de produtos via semente. Portanto, as aplicações de produtos que promovem uma melhor nutrição via semente desencadeiam uma melhora no metabolismo das plantas favorecendo a produção de algumas enzimas, como auxinas e citocininas, promovendo um maior crescimento e uma maior elongação da parte aérea com diferentes dosagens (TAIZ \& ZEIGER, 2004). 
Para o parâmetro altura de plantas (AP), o tratamento com acetato de zinco na dose de 4,0 $\mathrm{mL} \mathrm{kg}^{-1}$ de semente (T4) foi superior a todos os demais tratamentos, demonstrando que a aplicação do fertilizante com acetato de zinco promove uma maior formação da parte aérea, que consequentemente aumenta a produtividade $(\mathrm{P})$.

Na comparação das médias do parâmetro $\mathrm{P}$, a aplicação de acetato de zinco amoniacal na dose 2,0 mL kg-1 de semente promoveu maior produtividade em relação a todos os tratamentos, não diferindo estatisticamente dos tratamentos T4 e T5. Vieira et al. (1987) também encontrou resultados semelhantes ao aplicar Zn em sementes de soja, ocasionando um aumento na massa 100 grãos e a qualidade da semente não foi afetada.

Para os parâmetros massa fresca de raiz (MFR), massa seca de raiz (MSR) e número de vagens por planta (NVP), o tratamento com cobalto + molibdênio foi superior aos demais, confirmando os resultados encontrados por Sfredo \& Oliveira (2010). Nesses mesmos parâmetros os tratamentos T3 e T4 foram superiores ao controle absoluto e ao controle.

Na análise dos dados do parâmetro P à Fazenda Escola Capão da Onça, em Ponta Grossa, PR, na safra 2013/14, apresentou valores maiores que o encontrado na safra 2012/13.

Para o parâmetro AP, os tratamentos T3 e T4 com acetato de zinco amoniacal apresentaram os maiores valores, 45,93 e 46,33 centímetros, respectivamente, e foram superiores aos demais tratamentos. Na avaliação de MFR e MSR, os tratamentos T3, T4 e T5 obtiveram os maiores valores.

$\mathrm{Na}$ análise dos dados do parâmetro P na Fazenda Sonato, em Cornélio Procópio, PR, na safra 2014/15, o mesmo também apresentou valores maiores que o encontrado na safra 2012/13, mas foi semelhante a safra 2013/14.

Para o parâmetro AP, o tratamento T4 foi superior ao tratamento T1 e T2, mas não diferiu estatisticamente dos tratamentos T3 e T5. Para as características MFR e MSR os tratamentos T3, T4 e T5 da mesma maneira que nos resultados encontrados na safra 2013/14, obtiveram os maiores valores, confirmando que aplicação de produtos que promovem uma nutrição 
equilibrada no início da germinação e emergência, podem também promover uma maior MFR e MSR, mesmo em anos com bom regime hídrico.

O parâmetro P para a safra 2013/14 do tratamento T4 foi o maior, seguido pelo tratamento T3, diferindo dos demais tratamentos. Resultado similar foi encontrado na safra 2014/15, na qual os tratamentos T3 e T4 foram superiores a todos os demais. Há comprovações de que a aplicação de zinco às sementes aumenta o rendimento de grãos de soja (SANTOS \& ESTEFANEL, 1986). Porém, o fornecimento de zinco na semente pode não ser suficiente em suprir a necessidade total da planta, tendo de ser associado a doses menores deste nutriente aplicadas no solo (SANTOS \& RIBEIRO, 1986).

Apesar de não ter ocorrido deficiência hídrica na safra 2013/14 e 2014/15 os tratamentos que receberam a aplicação de acetato de zinco amoniacal (T3 e T4) e molibdênio + cobalto (T5), via semente obtiveram os maiores valores de MSR.

Observando os dados das três safras (2012/13, 2013/14 e 2014/15) na checagem das médias dos dados relativos a todos os parâmetros realizados, encontramos que os tratamentos que tiveram a adição de acetato de zinco amoniacal e de cobalto + molibdênio isoladamente, apresentaram diferenças significativas em todos os parâmetros avaliados em relação ao controle absoluto sem fertilizantes aplicados no plantio e sobre o controle sem aplicação de produtos via semente. Desta forma, na decisão sobre o tratamento de sementes com micronutrientes na soja, para que os resultados sejam diferentes, não devemos considerar apenas a produtividade final da cultura, mas sim o benefício que o mesmo trará para a planta, como índice de área foliar, desenvolvimento das plantas, enchimento de grãos e também uma análise econômica, se é ou não viável a aplicação do produto (FAVARIN \& MARINI, 2000).

Com essa quantidade de nutrientes fornecidas via tratamento de sementes, independentemente da dosagem, houve um aumento nos valores médios dos parâmetros avaliados, proporcionando com isso, uma maior absorção de água e nutrientes, uma maior produção de fotoassimilados, culminando assim em uma maior produtividade. 
A técnica de aplicação de nutrientes via sementes pode ser uma técnica complementar a adubação via solo, mas não é substitutiva, contudo, favorecendo o desenvolvimento inicial dos cultivos.

\section{CONCLUSÕES}

A aplicação do acetato de zinco amoniacal (ACA Plus) quanto à aplicação de cobalto e molibdênio, demonstrou incrementos significativos nas três safras (2012/13, 2013/14 e 2014/15) para os seguintes parâmetros: altura de plantas, massa fresca de raiz, massa seca de raiz e número de vagens planta ${ }^{-1}$.

As maiores produtividades foram proporcionadas pela aplicação do ACA Plus com a dose de $2,0 \mathrm{~mL} \mathrm{~kg}^{-1}$ de semente para a safra 2012/13 e 2014/15, e a dose de $4,0 \mathrm{~mL} \mathrm{~kg}^{-1}$ de semente para a safra 2013/14.

A aplicação de acetato de zinco amoniacal (ACA Plus) via semente é uma técnica viável e que pode melhorar o estande final das plantas de soja.

\section{REFERÊNCIAS BIBLIOGRÁFICAS}

BORKERT, C. M. Micronutrientes na planta. Interpretação de análise química de solo e planta para fins de adubação. Botucatu: Fundação de Estudos e Pesquisas Agrícolas e Florestais, 1986. p. 309-329.

CONAB. Acompanhamento da safra brasileira: Grãos safra 2014/2015. Conab, abril de 2015. Disponível em < http://www.conab.gov.br/OlalaCMS/uploads/arquivos/15_04_10_09_22_05_boletim_graos_a bril_2015.pdf >. Acesso em: 7 jul. 2015.

EMBRAPA. Recomendações técnicas para a cultura da soja no Paraná 1996/1997. Documentos 97. Londrina: Embrapa Soja, 1996. 187 p.

EMBRAPA. Sistema plantio direto. Brasilia: Embrapa, Serviço de Produção de Informação; Dourados: Embrapa CPAO, 1998. 248 p.

EMBRAPA. Sistema Brasileiro de classificação de solos. Brasilia: Embrapa, Produção de informação; Rio de Janeiro: Embrapa Solos, 2006. 306 p. 
EMBRAPA. Desenvolvimento, mercado e rentabilidade da soja brasileira. Circular técnica 74. Londrina: Embrapa Soja, 2010. 20 p.

EMBRAPA. Deficiências e Toxicidades de Nutrientes em Plantas de soja: descrição dos sintomas e ilustração com fotos. Documentos 231. Londrina: Embrapa Soja, 2004. 42 p.

FANCELLI, A.L.; Influência da nutrição de plantas na ocorrência de doenças e pragas. In: FANCELLI, A.L. \& DOURADO NETO, D. (Ed). Feijão irrigado - tecnologia de produtividade. Departamento de produção vegetal, Piracicaba: ESALQ/USP, 2003. p. 129.

FAQUIN, V. Nutrição Mineral de Plantas. Lavras: Editora UFLA / FAEPE, 2005. 186p.

FAVARIN, J.L.; MARINI, J P. A importância dos micronutrientes para a produção e grãos. A Lavoura, Rio de Janeiro, p. 29 - 31. 05 jun. 2000.

FERREIRA, D. F. SISVAR: Um programa para análises e ensino de estatística. Revista Symposium, Lavras, v.6, p.36 - 42, 2008.

INSTITUTO BRASILEIRO DE GEOGRAFIA E ESTATÍSTICA. Estatística da produção agrícola (LSPA). Jan. 2013. Disponível em: < http://www.ibge.gov.br> Acesso em: julho de 2013>. Acesso em: 05 jul. 2015.

KOEHLER, H.S. Estatística experimental. Curitiba: UFPR. Departamento de Fitotecnia, 124 p., 1994.

MALAVOLTA, E.; BOARETTO, A. E.; PAULINO, V. T. Micronutrientes: uma visão geral. In: FERREIRA, M. E; CRUZ, M. C. P. Micronutrientes na agricultura. Piracicaba: POTAFÓS, 1991. p. 1-34.

MALAVOLTA, E.; VITTI, G.C.; OLIVEIRA, S.A. Avaliação do estado nutricional das plantas: princípios e aplicações. Piracicaba: POTAFÓS, 2 ed., 1997. 319 p.

MENGEL, K.; KIRKBY, E.A. Principles of plant nutrition. Bern : International Potash Institute, 1987. $687 \mathrm{p}$.

PACHOLCZAK, A.; SZYDLO, W. Effect of ammonium zinc acetate on rooting of stem cuttings in Physocarpus opulifolius. Ann Warsaw Univ. Life Sciences - SGGW. Hotic. Landsc. Architect. 29, 2008. p. 59-64.

PARDUCCI, S., SANTOS, O.S., CAMARGO, R.P. Micronutrientes Biocrop. Campinas: Microquímica, 1989. 101 p.

RIBEIRO, N. D.; SANTOS, O. S. Aproveitamento do zinco aplicado na semente na nutrição da planta. Ciência Rural, Santa Maria, v. 26, n. 1, p. 159-165. Abr. 1996.

SANTOS, O.S. O zinco na nutrição de plantas leguminosas. Lavoura Arrozeira, v. 34, n. 330, p. $26-32.1981$. 
SANTOS, O. S.; ESTEFANEL, V. Efeito de micronutrientes e do enxofre aplicados nas sementes de soja. Rev. Centro Ciências Rurais, Santa Maria, v. 16, n. 1, p. 5 - 17, 1986.

SANTOS, O. S.; RIBEIRO, N. D. Fontes de zinco aplicadas em sementes de milho, em solução nutritiva. Rev. Centro Ciências Rurais, v. 1, p. 39 - 44, 1986.

SEDIYAMA, T.; PEREIRA, M.G.; SEDIYAMA, C.S.; GOMES, J.L.L. Cultura da soja: parte I. Viçosa: UFV, 1993. 97 p.

SFREDO, G.J.; OLIVEIRA, M.C.N.; Soja: molibdênio e cobalto. Documentos 322. Londrina: Embrapa Soja, 35 p. 2010.

TAIZ, L.; ZEIGER, E. Fisiologia vegetal. Porto Alegre: Artmed, p. 449 - 484. 2004.

VIEIRA, R.D.; CARVALHO, N.M.; BUZETTI, S. Efeito da adubação com zinco sobre a qualidade fisiológica de Sementes de soja. Revista Brasileira de Sementes, vl. 9, n. 1, p. 107-111, 1987.

YAMADA, T. A. Nutrição mineral e a resistência das plantas às doenças. Piracicaba: POTAFOS. Informações Agronômicas. n. 72, 1995. 